Acquisitions are beginning to play their expected role in biotech's development. In the largest move, Eli Lilly is paying an estimated $\$ 300$ million or more to acquire monoclonal antibody specialist Hybritech (San Diego, CA). Also, France's Rhone-Poulenc paid an undisclosed amount to buy privately held Purification Engineering Inc. (Columbia, MD), which uses immobilized cell technology.

Wall Street analysts perceive logical "fits" between both sets of partners, but for different reasons. Hybritech will give Lilly an instant entrance into the diagnostic marketplace. In the future, however, it could be Hybritech's work with therapeutic monoclonals for cancer that will prove most valuable to Lilly. Rhone-Poulenc will use PEI as a biotechnology base for its U.S. operations.

In an innovative financing move, part of Hybritech's purchase price comes in the form of tradeable Contingent Payment Units, the value of which will depend on Hybritech's operating performance over the next decade. According to Hybritech, these units could turn out to be worth up to $\$ 22$. Analysts look favorably on the arrangement noting that it allows Hybritech shareholders to maintain a "play" in the company. Included in this group of shareholders, of course, are Hybritech's key personnel, who now have financial incentive to remain with the company and strive for its success.

Plants can now be patented in the U.S., according to Molecular Genetics (Minnetonka, MN). The company reports that the U.S. Board of Patent Appeals and Interferences has reversed the long-standing policy against the patentability of seeds, plants, and plant tissue cultures. Molecular Genetics, through the Molecular Genetics Research and Development Limited Partnership, hopes to be able to patent new corn seeds and plants that have high levels of tryptophan.

The new chief executive officer for the Biogen Group is James L. Vincent, who had been group vice president of Allied-Signal Inc. (Morristown, NJ) and president of its Health and Scientific Products Company. Vincent fills a void created last winter with the resignation of founder Walter Gilbert. According to Vincent, it is too early for him to talk about potential changes and directions at Biogen.
As for his departure from Allied, Vincent stresses, "it was not a 'leavefrom,' but a 'go-to' decision."

Separately, Biogen reported "promising" results in using its gamma interferon to treat rheumatoid arthritis. According to Seth A. Rudnick, Biogen's senior vice president for pharmaceutical development, the company initiated clinicals in West Germany and the U.S. after cancer patients who happened to also have rheumatoid arthritis showed improvement following administration of Immuneron ${ }^{\circledR}$. This is somewhat surprising because gamma interferon is a stimulator of the immune system. "If you were to make a bet, you'd say that gamma interferon should make rheumatoid arthritis worse, not better," Rudnick notes. However, he postulates, the substance might serve to stimulate some kind of suppressor system.

"It will be the first product out of this industry that is a real product for everyday use that is not in health care," says Steven Lee, president of Repligen Corp. (Boston, MA). The as-yet-unidentified hair product is the first to come out of Repligen's collaboration with Gillette (Boston, MA), now involved in the development of four products, according to Lee. The hair product is scheduled for introduction in Europe early next year, and in the U.S. toward the middle of 1986.

New agreements involving biotech companies include:

- Cytogen Corp. (Princeton, NJ) and Farmitalia Carla Arba SpA will jointly develop cytotoxic drug-monoclonal antibody conjugates for the treatment of cancer. The research will combine Cytogen's linker technology with Farmitalia's anthracycline cytotoxic agents.

- Rothschild, Inc., through several venture capital funds for which it acts as an advisor, plans to provide Applied Biosystems (Foster City, CA) with $\$ 3.1$ million in research funding over the next two years.

- Imperial Biotechnology Ltd. (London) and the U.K. Dairy Industry Research Policy Committee signed a three-year, $£ 100,000$ agreement for the development of an enzymatic system for maturation of cheddar cheese.

- E.I. du Pont de Nemours (Wilmington, DE) purchased an option through the end of this year to license the acquired immune deficiency syndrome screening test developed by Molecular Biosystems (San Diego, CA).

- Biosearch (San Rafael, CA) has agreed with Biosyntech Biochemische Synthesetechnik GmbH (Biosyntech, Hamburg, F.R.G.) to market cyanoethyl amidites, which are used to make synthetic DNA. The two firms will also cooperate on other product developments.

- Fisher Scientific (Pittsburgh, PA) will distribute a portion of the molecular biology product line of Promega Biotec (Madison, WI).

- Bioproducts for Science, Inc. (BSI, Indianapolis, IN) has become the exclusive U.S. distributor for the immunological and biological products produced by Serotec Ltd. (Bicester, U.K.).

The first human clinical trials of tumor necrosis factor have been initiated on cancer patients by Genentech (South San Francisco, CA). The Phase I trials to determine safe dosages are taking place at Memorial Sloan-Kettering Cancer Center (New York) and M.D. Anderson Hospital (Houston).

\section{In research news:}

- The structure of the common cold virus has been elucidated by researchers at Purdue University (West Lafayette, IN). The group, headed by Michael G. Rossman, used a supercomputer to solve the structure of human rhinovirus-14, one of a hundred known strains of the common cold virus.

- California Biotechnology (Mountain View, CA) reported that it has discovered three genetic markers that correlate with susceptibility to heart disease.

- Scientists at the La Jolla Cancer Research Foundation identified and isolated the cell surface receptors for fibronectin and vitronectin, glycoproteins that help hold cells in their proper places within body tissues.

Construction has begun on two biotechnology installations. Damon Biotech (Needham Heights, MA) has broken ground on its $\$ 40$ million manufacturing facility in Scotland, which will be known as the Damon Biotechnology Centre. Also, the expansion of laboratories is underway at the Scripps Clinic (La Jolla, CA) to accommodate the $\$ 120$ million joint venture with PPG Industries. 